\title{
Is the finding of obsessional behaviour relevant to the differental diagnosis of Vascular Dementia of the Binswanger Type?
}

\author{
Robert M. Lawrence \\ Neurodegeneration Research Group, Jenner Wing, \\ Level 01, St George's Hospital Medical School, \\ Cranmer Terrace. Tooting, London, SW17 ORE, UK \\ Tel.: +44 208725 3519; Fax: +44 208682 0926; \\ E-mail: rlawrenc@sghms.ac.uk
}

Revised 24 July 2000

Whilst carrying out a pilot study with a structured questionnaire examining the difference in insight between a group of patients with Alzheimer's Disease and a second group with Vascular Dementia of the Binswanger Type, the incidental observation was made that the group of patients with Vascular Dementia of the Binswanger Type demonstrated more obsessional behaviour than the group of patients with Alzheimer's Disease. The obsessional behaviour differed from classical obsessive compulsive disorder insofar as the subjects were unaware of it whilst at the same time resisting change.

Keywords: Vascular dementia, Binswanger's Disease, obsessional behaviour

\section{Introduction}

White matter disease is found in 70-90\% cases of vascular dementia and is associated with a history of raised blood pressure, heart disease and diabetes. The psychopathology is represented by transient episodes of clouding of consciousness, slowing of mental processing, patchy psychological deficits, impaired attention and concentration [1], mood lability and increased risk of developing symptoms of depression and anxiety. Early symptoms may also include diminished judgement and behavioural extremes, such as apathy and social withdrawal appearing alongside disinhibition, irritability and aggressiveness [24,25,33]. Binswanger's Disease, also known as Subcortical Arteriosclerotic Encephalopathy or Dementia of the Binswanger Type is a clinicopathological syndrome arising in middle aged or elderly people with a history of high blood pressure and is accompanied by cortical and subcortical deficits. As a form of Vascular Dementia it is relatively rare and said to affect men more than women $[2,4,5,13,17$, 23]. The neuropathology is that of a progressive white matter demyelination with thickening of penetrating medullary arteries, which causes a subcortical-cortical disconnection dementia [13,19,32,35,38].

Stereotyped and repetitive behavioural features have been described in subcortical dementias and also in association with abnormalities of the frontal lobes and basal ganglia. Discrete vascular lesions have been implicated in the pathogenesis of obsessionality $[6,38,40$, 41]. In 1995 Swodoba demonstrated obsessional behaviour arising de novo in a 70 years old man following a right frontal infarction [39].

The occurrence of obsessional features has also been described in cases of focal cortical degeneration with PET hypometabolism in the frontal lobes and/ or adjacent dominant temporal lobes [22].

Whilst comparing the psychopathology of two groups of demented patients suffering from Alzheimer's Disease and of Vascular Dementia of the Binswanger Type, it was observed that the latter displayed patterns of obsessional behaviour more frequently. This was a serendipitous yet striking finding, the context of which is explained in this paper.

\section{Method}

\subsection{Selection of subjects}

Patients under the care of Old Age Psychiatrists, Geriatricians and Neurologists at St George's Hospital, Warlingham Park Hospital, Crawley Hospital and Princess Royal, Haywards Heath, were screened and underwent a preliminary selection process. The diag- 
nosis of Alzheimer's Disease or Binswanger's Disease was made on the basis of the clinical history, presentation, diagnostic criteria and CT brain scan results. The study protocol was submitted to each Local Research Ethics Committee and ethical approval was obtained. Each patient signed a consent form that was countersigned by their nearest relative/primary carer, who also contributed to the study as collateral informant. The protocol required that the informant should have known and continuously supervised the patient for a minimum of two years prior and up to the assessment.

The study involved a preliminary phase of strict selection. In order to enter the preliminary phase of the study, subjects were to be older than 45 years of age and without any physical or systemic pathology which might have had a pathoplastic effect on their dementing illness and be incompatible with the diagnostic criteria for the same. The patients' and carers' native language must be English and adequate hearing and visual aids were to be worn if required.

All the subjects selected to enter the Alzheimer's Disease group satisfied the following criteria: 1) a diagnosis of Probable Alzheimer's Disease according to NINDS-ADRDA criteria [26]; 2) the CT brain scan showing mild/moderate global atrophy and/or mild/moderate bilateral temporo-parietal atrophy; 3) no history of hypertension, epilepsy, CVAs, diabetes, abnormal thyroid functions or any other multisystem/endocrinological disease; 4) Hachinski score lower than 4 [15]. All the subjects selected to enter the group with Dementia of the Binswanger Type 1) satisfied diagnostic criteria for vascular dementia (NINDS-AIREN) and research diagnostic criteria for Binswanger's Disease [1,34] 2) CT brain scan showed marked diffuse white matter disease, 3) they had no history of diabetes, abnormal thyroid function or other multi-system endocrinological disease, 4) the Hachinski score was higher than 4.

Subjects passing through the initial screening process were further investigated with instruments designed to elicit premorbid intellectual levels, cognitive dysfunction, behavioural disturbance, mood disturbance and psychotic symptoms such as delusions and hallucinations. These included the National Adult Reading Test (NART) [27], Mini Mental State Examination Test [10], Finger Tapping [36] and Weigl Card Sorting Test [42], the Hamilton Depression Scale [16], the Stockton Geriatric rating Scale (SGRS) [14], and sections from the Geriatric Mental State (GMS) [8] on Worry, Depression, Tension, Somatic Dysfunction, Thinking Difficulties and Slowness, Hyperactivity, Ela- tion, Grandiosity, Social Discomfort, Delusions of Persecution and Reference, Self Depreciation, Irritability, Obsessions, Interest and Perceptual Difficulties.

Each subject was subsequently interviewed with a structured questionnaire piloted to identify the existence of insight in the different aspects of psychopathology. The questionnaire, Lawrence Insight Structured Assessment Battery (LISAB) [21], was being developed to assess insight in psychopathology objectively reported by patient, carer and researcher to the exclusion of insight for non observable symptoms. The questionnaire was divided into the three major psychopathological domains of 1)Memory and Language 2) Emotional Behaviour and 3) Social Behaviour with subcategories derived by reference to the Present State Examination [21,43].

In the questionnaire technical language was avoided and consideration given to the limitations of dysphasic patients by using direct questions and "yes/no" answers. In each domain, a record of insight was obtained. The patient rated his degree of insight as lack of awareness/concern ("not at all"), fair degree or awareness/concern ("slightly/fairly concerned"), complete awareness/concern ("considerably/very concerned" and ratings from [0] (= no attributed insight) to [4] (= completely attributed insight) were available to the informant and the researcher. Records did not carry a definite mathematical meaning, rather the indication of the presence of insight and some information of its intensity.

The pilot sample therefore included 18 subjects, 11 with a diagnosis of Probable Alzheimer's Disease (NINCDS Criteria) and 7 with a diagnosis of Vascular Dementia of the Binswanger Type (Table 1).

Inter-rater reliability was assessed on all completed sections of the insight questionnaire with Kappa statistics, the value of kappa judged by $\mathrm{z}$ statistics(two-sided significance test). For the purpose of two-tailed nonparametric analysis of insight, the category of sexual behaviour was finally excluded as only one out of 22 cases reported psychopathology (sexual disinhibition). False positive were also excluded (i.e. symptoms are not observable whilst patient expressed awareness of the same).

\section{Results}

During this pilot phase 22 patients were successfully screened but 4 informants failed to complete the sections on collateral information. The Alzheimer's Dis- 
Table 1

Alzheimer's Disease (AD) and Binswanger's Disease (BD) groups

\begin{tabular}{|c|c|c|c|c|}
\hline & $\begin{array}{c}\mathrm{AD} \\
n=11 ; \\
7 \text { females } 4 \text { males }\end{array}$ & $\begin{array}{c}\text { BD } \\
n=7 \\
5 \text { females } 2 \text { males }\end{array}$ & chi-square & $\begin{array}{c}\mathrm{s} / \mathrm{ns} \\
(p=)\end{array}$ \\
\hline Males/Females & $4 / 7$ & $2 / 5$ & 0.12 & $p=0.57(\mathrm{~ns})$ \\
\hline Mean Age & $79.1(\mathrm{SD} 4.9)$ & $75.1(\mathrm{SD} 6.0)$ & 1.3 & $p=0.254(\mathrm{~ns})$ \\
\hline Mode & 75 & 78 & & \\
\hline $\begin{array}{l}\text { Range } \\
\text { (males) Mean Age } 79.7 \\
\text { (SD 4.4) }\end{array}$ & $(70-75)$ & $(65-82)$ & & \\
\hline $\begin{array}{l}\text { (females) Mean Age } 76.6 \\
\text { (SD 6.0) }\end{array}$ & & & 0.7 & $p=0.39(\mathrm{~ns})$ \\
\hline mean NART & 23.7 (SD 15.3) & $18.1(\mathrm{SD} 9.83)$ & 0.52 & $p=0.5(\mathrm{~ns})$ \\
\hline mean MMSE & $14.0(\mathrm{SD} 8.44)$ & $14.4(\mathrm{SD} 8.58)$ & 0.008 & $p=0.9(\mathrm{~ns})$ \\
\hline mean HDS & $9.18(\mathrm{SD} 3.92)$ & $13.57(\mathrm{SD} 6.26)$ & 3.32 & $p=0.081(\mathrm{~ns})^{*}$ \\
\hline mean SGRS & $12.4(\mathrm{SD} 6.0)$ & $13.6(\mathrm{SD} 7.4)$ & 0.05 & $p=0.82(\mathrm{~ns})$ \\
\hline $\begin{array}{l}\text { Ritualistic } \\
\text { behaviour }\end{array}$ & $5 / 11$ & $7 / 7$ & 14.49 & $\begin{array}{l}p=0.0034 \text { (s) } \\
\text { (Fisher's Exact Two } \\
\text { Tailed Test) }\end{array}$ \\
\hline
\end{tabular}

*approaching significance.

ease group was composed of 11 subjects, 7 women and 4 men. The group with Vascular Dementia of the Binswanger Type was composed of 7 subjects, 5 women and 2 men.

A difference between the two groups was found in the record of obsessional behaviour, less frequent in the AD group $(\mathrm{AD}=5 / 11 ; \mathrm{VaD}=7 / 7)$ (Fisher exact two tailed $\mathrm{p}$ value $=0.034$.). The intensity of obsessional behaviour was mild in the subjects with Alzheimer's Disease and consisted mainly of increased orderliness. In the group with Senile Dementia of the Binswanger Type, symptoms appeared to be more severe, including rigid daily rituals, repeated checking and toilet rituals (Table 2). These symptoms were non ego-dystonic and patients did not tolerate attempts at distraction from carrying out the behaviour.

\subsection{Vignettes}

Here are three examples of the behaviour in question:

- 79 year old right handed female with a 4-6 years history of a Vascular Dementia of the Binswanger Type and a Mini Mental State Score of 2, engaged in fixed checking rituals of doors and objects about the house and repeated toilet rituals, with hand and face washing continuing for hours. Attempts at distraction from the rituals would result in her becoming very upset and agitated.

- 65 year old left handed female with a 2-3 years history of Vascular Dementia of the Binswanger Type and a Mini Mental State score of 12, who would daily visit her backyard and line up all the flower pots upside down in a line right in the middle of the garden, returning them to their place only to repeat the activity a few hours later. She would not allow anyone to displace the pots whilst she was lining them up.

- 78 year old left handed female with a one year history of Vascular Dementia of the Binswanger Type and a Mini Mental State of 26, who would daily and at the same time each day go "shopping". She would walk to the same shop and acquire always the same items. She would become agitated if asked to change the time of her outing, the route or not go to the shop.

\subsection{Profile of insight (preliminary descriptive analysis)}

Awareness for memory problems seemed to peak in the mid-range of MMSE scores (11-20) for the vascular group but not so in the group with Alzheimer's Disease, where awareness appeared to increase with lesser MMSE scores.

In the group with Alzheimer's Disease, there was more awareness of symptoms of mood dysphoria in the moderately depressed subjects scoring between 8 and 15 on the Hamilton Depression Score. Awareness diminished with scores of 16 and above.

As for competence in general self care, more insight was on this occasion recorded with increasing dependency in subjects with Vascular Dementia of the Binswanger Type. The subjects with Alzheimer's Disease were generally less aware of their increasing dependency. 
Table 2

Obsessional behaviour in the Alzheimer's Disease (AD) and Binswanger's Disease Groups (BD)

\begin{tabular}{|c|c|c|c|}
\hline$\overline{\mathrm{AD} \text { cases }}$ & Sex/Aet & Ritualistic behaviour & CT Brain scan \\
\hline 1 & $\mathrm{M} / 75$ & unremarkable & gen. atrophy \\
\hline & & & mild small vessel disease \\
\hline 2 & $\mathrm{M} / 81$ & increased orderliness $(+)$ & gen. Atrophy \\
\hline 3 & $\mathrm{M} / 84$ & mealtimes rituals $(+)$ & gen. atrophy (mild) \\
\hline 4 & $\mathrm{M} / 85$ & unremarkable & gen.atrophy \\
\hline 5 & $\mathrm{~F} / 70$ & fixed routines $(+)$ & gen. Atrophy \\
\hline 6 & $\mathrm{~F} / 75$ & increased orderliness $(+)$ & gen.atrophy (mild) \\
\hline 7 & $\mathrm{~F} / 77$ & unremarkable & gen.atrophy \\
\hline & & & mild small vessel disease \\
\hline 8 & $\mathrm{~F} / 77$ & fixed routines $(+)$ & gen.atrophy (mild) \\
\hline 9 & $\mathrm{~F} / 78$ & unremarkable & gen. atrophy (mild) \\
\hline 10 & $\mathrm{~F} / 84$ & unremarkable & gen.atrophy \\
\hline 11 & $\mathrm{~F} / 85$ & unremarkable & gen.atrophy(mild) \\
\hline \multicolumn{4}{|l|}{ BD cases } \\
\hline 1 & $\mathrm{M} / 75$ & increased orderliness $(+)$ & white matter disease \\
\hline 2 & $\mathrm{M} / 78$ & increased orderliness $(++)$ & white matter disease \\
\hline 3 & $\mathrm{~F} / 65$ & fixed routines $(++)$ & $\begin{array}{l}\text { white matter disease } \\
\text { right frontal focal ischaemia }\end{array}$ \\
\hline 4 & $\mathrm{~F} / 69$ & fixed routines $(++)$ & white matter disease \\
\hline 5 & $\mathrm{~F} / 78$ & fixed routines $(++)$ & white matter disease \\
\hline 6 & $\mathrm{~F} / 79$ & checking/toilet rituals $(++)$ & white matter disease \\
\hline 7 & $\mathrm{~F} / 82$ & checking rituals $(++)$ & white matter disease \\
\hline
\end{tabular}

Key to symbols: $+=$ mild obsessional symptoms;

$++=$ marked obsessional symptoms present

\section{Discussion}

The observation of obsessional behaviour was serendipitous in the context of a pilot study used to develop an instrument to assess the presence of insight in different types of dementia. No scientific conclusions can be drawn from the preliminary observations on insight whilst further validation is in process, but the obsessional symptoms in the group of patients with Vascular Dementia of Binswanger Type deserve attention.

The method of initial screening, selection of subjects and diagnosis was strict. For an uncommon diagnosis known to be rarer in women, the diagnostic rigour might partly explain why more women than men were selected in the vascular group. It was in the process of reviewing the characteristics of the two selected groups that the observation of a difference in the frequency of presentation of obsessive phenomena was made. Whilst it is accepted that our findings may be biased by the limited sample and previous anecdotal experience, it was felt that these might still warrant attention in their own right with regard to the possibility of some relevance to the early diagnosis of this type of dementia.

Subcortical and periventricular infraorbital areas are primary targets of subacute arteriosclerotic en- cephalopathies. All our cases presented similar radiological findings of marked leukoaraiois in these regions compared with less intense pathology in the AD group. In all seven patients the periventricular white matter disease spread across periventricular areas and frontal horns, and in one case it was also accompanied by a small focal right frontal ischaemia.

Organic personality changes in cerebrovascular disease were described by Slater as far back as 1962, patients avoiding new experiences and restricting themselves to routines [24,25]. These patients would also develop hypochondriacal preoccupations and later show inflexible emotional reactions.

The symptoms we observed were in the context of a chronic organic syndrome. In the absence of a clearly identifiable neurotic core, and since the primary diagnosis would be that of a dementing illness, the diagnosis of an obsessive compulsive disorder was not applicable. Classical obsessive compulsive disorders are characterised by ego-dystonic feelings, ideas and ensuing actions caused by subjective compulsion which must be resisted and are perceived by the patient as coming from within the self. The symptoms are ego-dystonic insofar as the patient does not feel attuned to these, knows well that they come from within him, does not welcome but cannot help them at the same time. The ritualistic behaviour arises in an attempt to alleviate the 
anxiety caused by the compulsion and the patients are often embarrassed by their experience, even attempting to conceal its occurrence from others. In functional obsessive compulsive disorder abnormal activity involving the orbitofrontal cortex, cingulated gyrus and caudate nucleus has been suggested by findings of increased metabolic activity in these areas on SPECT and PET scanning whilst MRI scanning has not confirmed any specific structural brain abnormalities [18,20,28].

In our cases with Senile Dementia of the Binswanger Type with obsessional manifestations, the patients did not seem to be aware of these, did not complain or attempt to resist the drive to carry out the behaviour, but became agitated if anybody challenged the same. In this way, the obsessional behaviour found in our cases was atypical for classical obsessive compulsive disorder and closer to that seen in Encephalitis Lethargica or in Gilles de la Tourette syndrome. In the latter the pathogenesis is still partly unclear but basal ganglia, thalamus and fronto-temporal areas have all been implicated, as the discrete hypoperfusion on PET and SPECT scanning indicates [3,7,29-31]. The ritualistic behaviour in our cases further bears affinity with autistic behavioural patterns such as repetitive elaborate routines and bizarre preoccupations. These have also been attributed to dysfunction of basal ganglia and frontal lobes [7,9,11,12,44].

Obsessional behaviour with hypoperfusion of infraorbital areas has been reported in cases of focal cortical degeneration [22]. In Binswanger's Disease, the arteriosclerotic encephalopathy affects the long perforating vessels to the deep white matter. Leukoaraiosis progresses from basal to infra-orbital and more peripheral periventricular frontal areas $[15,19,33,37]$. It is in consequence inferred that, as the white matter damage progresses and the limbic-frontal areas are progressively affected, frontal functions of judgement and organisation of behaviour may be slowly eroded with their organic substratum. The hypothesis is therefore put forward that the limbic-frontal progressive demyelination would initially generate the pattern of regression into rigidity of behavioural patterns, finally leading to insightless and automatic obsessional patterns and "undoing" rituals. At the same time, the awareness of the appropriateness or inappropriateness of such actions would be lost.

\section{Conclusion}

The onset of non ego-dystonic obsessional behaviour in patients with varying degrees of cognitive dysfunc- tion might therefore be of some relevance in the differential diagnosis between Alzheimer's Disease and Vascular Dementia of the Binswanger Type. A reliable differential diagnosis would continue to impinge on a history of cerebrovascular disease and other risk factors such as a hypertension and heart disease.

Our sample is too small to allow final conclusions but intriguing enough to raise a hypothesis for further investigation. The question to examine will be whether this was the serendipitous result of a recruitment process or whether it might have a broader clinical significance.

\section{Acknowledgments}

This paper formed part of an MPhil Degree in Neuropsychiatry. My thanks to Professor Peter H Millard and Dr John Kellett, St George's Hospital Medical School, for their support and advice.

\section{References}

[1] K. Amar and G. Wilcock, Vascular Dementia, British Medical Journal 312 (1996), 227-231.

[2] D.A. Bennett, R.S. Wilson, D.W. Gilley and J.H. Fox, Clinical Diagnosis of Binswanger's Disease, Journal of Neurology, Neurosurgery and Psychiatry 53 (1990), 961-965.

[3] E.E. Caine, M.C. McBride, P. hiverton, K.A. Bamford and S. Reidiess, Shiao, Tourette syndrome in Monroe County school children, Neurology 38 (1988), 472-475.

[4] L.R. Caplan and W.C. Schoene, Clinical features of subcortical encephalopathy (Binswanger's Disease), Archives of Neurology 28 (1978), 1206-1215.

[5] L.R. Caplan and W.C. Schoene, Clinical features of subcortical ATS encephalopathy (Binswanger's Disease), Archives of Neurology 42 (1985), 951-959.

[6] M.K. Chilters, D. Holland, M.G. Ryan and J. Rupright, Obsessional disorders during recovery from severe head injury: report of four cases, Brain Injury 12(7) (1998), 613-616.

[7] H. Claude, H. Baruk and A. Lamache, Obsessions-impulsions consecutives a l'encephalite epidemique, Encephale 22 (1927), 716-720.

[8] J.R.M. Copeland, M.J. Kelleher and J.M. Kellett et al., A semi-structured clinical interview for the assessment of diagnosis and mental state in the elderly: The Geriatric Mental State Schedule: I, development and reliability, Psychological Medicine 6 (1976), 439-449.

[9] J.G. Eapen and G.K. Shaw, Frontal glioma presenting as anxiety and obsessions: a case report, Acta Neurologica Scandinavica 96(3) (1997), 194-195.

[10] M.F. Folstein, S.E. Folstein and P.R. McHugh, Mini Mental State. A practical method for grading the cognitive state of patients for the clinician, Journal of Psychiatric Research 12 (1975), 189-198.

[11] U. Frith, Cognitive explanations of autism, Acta Pediatrica Supplement 416 (1996), 63-68. 
[12] U. Frith and F. Happe, Autism: beyond "theory of mind", Cognition 50(1-3) (1994), 115-132.

[13] J. Ghika and J. Bogousslavsky, White Matter Disease and Vascular Dementia, in: Vascular Dementia Current Concepts, (vol. 5), I. Prohovnik, J. Wade, S. Knezevic, T. Tatemichi and T. Erkinjuntti, eds., 1996, pp. 113-141.

[14] C.J. Gilleard and A.H. Pattie, The Stockton Geriatric Rating Scale: A shortened version with British normative data, British Journal of Psychiatry 131 (1977), 90-94.

[15] V.C. Hachinski, L.D. Iliff and E. Zilkha et al., Cerebral blood flow in dementia, Archives of Neurology 32 (1975), 632-637.

[16] M. Hamilton, Development of a rating scale for primary depressive illness, British Journal of Medical Psychology 32 (1967), 50-55.

[17] K. Huang, L. Wu and Y. Luo, Binswanger's Disease: progressive subcortical encephalopathy or multi infarct dementia, Canadian Journal of Neurological Science 12 (1985), 89-94.

[18] T.R. Insel, Towards a neuroanatomy of obsessive compulsive disorders, Archives of General Psychiatry 49 (1992), 739-744.

[19] D. Inzitari, F. Diaz, A. Fox, V.C. Hachinski, A. Steingart and C. Lau, Vascular risk factors and leuko-araiosis, Archives of Neurology 44 (1987), 42-47.

[20] C. Kellner, R. Jolley and R. Holgate, Brain MRI in obsessivecompulsive disorder, Psychiatry Research 36 (1991), 45-49.

[21] R.M. Lawrence, A Study of cognitively impaired patients. The creation of a structured interview schedule for the evaluation of insight in dementia, MPhil Thesis (Neuropsychiatry), St George's Hospital Medical School, University of London, 1997.

[22] R.M. Lawrence, M.A. Ron, P. Tyrrell and M.N. Rossor, Psychiatric symptoms in patients with focal cortical degenerations, Behavioural Neurology 7 (1994), 153-158.

[23] R.M. Lawrence and J. Hillam, Psychiatric symptomatology in early onset Binswanger's Disease: two case reports, Behavioural Neurology 7 (1995), 153-158.

[24] W.A. Lishman, Arteriosclerotic dementia, in: Organic Psychiatry, (2nd ed.), Blackwell Scientific Publications, 1987, pp. 385-391.

[25] W.A. Lishman, Cerebrovascular disorders, in: Organic Psychiatry, (3rd ed.), Blackwell Science, 1998, pp. 375-427.

[26] G. McKhan, D. Drachman, M. Folstein, R. Katzaman, D. Price and E.M. Stadlan, Clinical Diagnosis of Alzheimer's Disease: report of the NINCDS-ADRDA work group under the auspices of the Department of Health and Human Services task Force on Alzheimer's Disease, Neurology 34 (1984), 939-944.

[27] H.E. Nelson and J.R. Willison, The National Adult Reading Test, (2nd ed.), NFER-Nelson, Windsor, 1991.

[28] S.I. Rauch, M.A. Jenike and N.M. Alpert, Regional cerebral blood flow measured during symptom provocation in obsessive-compulsive disorder using oxygen 15-labeled carbon dioxide and positron emission tomography, Archives of General Psychiatry 51 (1994), 62-70.

[29] M.M. Robertson, Annotation: Gilles de la Tourette syndrome -an update, Journal of Child Psychology and Psychiatry 35 (1994), 597-611.

[30] M.M. Robertson and J.S. Stern, The Gilles de la Tourette syndrome, Critical Reviews in Neurobiology 11(1) (1997), 119.

[31] M.M. Robertson, M.R. Trimble and A.J. Lees, The psychopathology of Gilles de la Tourette syndrome, British Journal of Psychiatry 152 (1988), 383-390.

[32] G.C. Roman, Senile Dementia of the Binswanger's Type: a vascular form of dementia in the elderly, Journal Of the American Medical Association 258 (1987), 1782.

[33] G.C. Roman, Vascular Dementia today, Revue Neurologique 155(4) (1999), S64-72.

[34] G.C. Roman, T.K. Tatemichi and T. Erkinjuntti et al., Vascular Dementia: diagnostic criteria for research studies. Report of the NINCDS-AIREN International Workshop, Neurology 43 (1993), 250-260.

[35] R.T. Rubin, J. Villanueva-Meyer and J. Ananth, Regional xenon 133 cerebral blood flow and cerebral technetium Tc99m-HMPAO uptake in unmedicated patients with cerebrovascular disorder and match normal control subjects, Archives of General Psychiatry 49 (1992), 695-702.

[36] E.W. Russell, C. Neuringer and G. Goldstein, Assessment of Brain Damage, Wiley, New York, 1970.

[37] P. Summergrad and B. Peterson, Binswanger's Disease (Part I): The clinical recognition of subcortical arteriosclerotic encephalopathy in elderly neuropsychiatric patients, Journal of Geriatric Psychiatry and Neurology 2(3) (1989), 123-133.

[38] S.E. Swedo, S.L. Rapoport and D.L. Shelslow, High prevalence of obsessive compulsive symptoms in patients with Sydenham's chorea, American Journal of Psychiatry 146 (1989), 246-249.

[39] K.J. Swodoba and M.A. Jenike, Frontal abnormalities in a patient with obsessive-compulsive disorder: the role of structural lesions in obsessive-compulsive behaviour, Neurology 45 (1995), 2130-2134.

[40] C. Ward, Transient feelings of compulsion caused by hemispheric lesions: three cases, Journal of Neurology Neurosurgery and Psychiatry 51 (1988), 447-448.

[41] J.B. Weilburg, M.M. Mesulam, S.Weintraub, F. Buonanno, M. Jenike and J.W. Stakes, Focal striatal abnormalities in a patient with obsessive-compulsive disorder, Archives of Neurology $\mathbf{4 6}$ (1989), 233-235.

[42] E. Weigl, On the psychology of the so-called process of abstraction, Journal of Abnormal and Social Psychology $\mathbf{3 6}$ (1941), 33.

[43] J.K. Wing, J.E. Cooper and N. Sartorious, Measurement and classification of psychiatric symptoms, Cambridge University Press, 1974.

[44] L. Wing, Language, social and cognitive impairment in autism and severe mental retardation, Journal of Autism and Developmental Disorders 11(1) (1981), 31-44. 


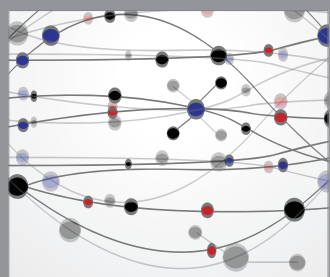

The Scientific World Journal
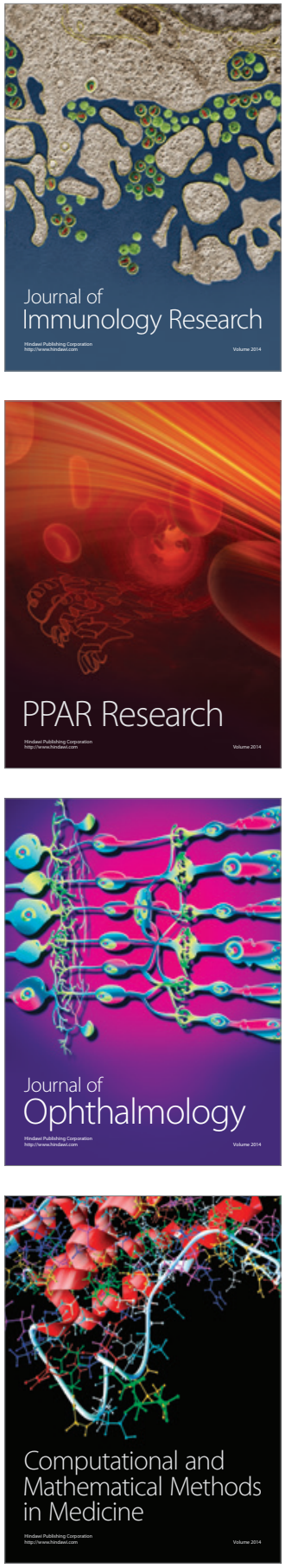

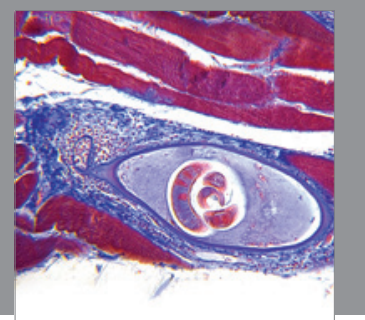

Gastroenterology

Research and Practice
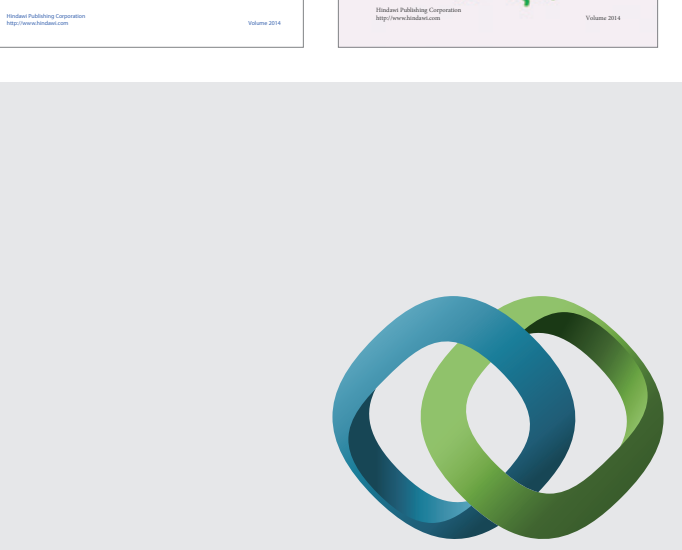

\section{Hindawi}

Submit your manuscripts at

http://www.hindawi.com
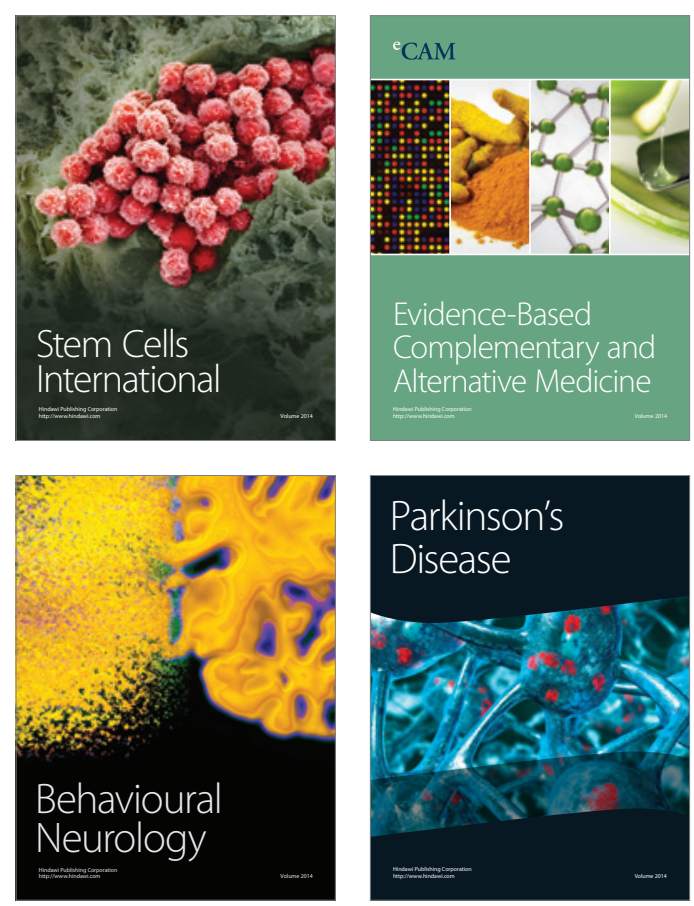

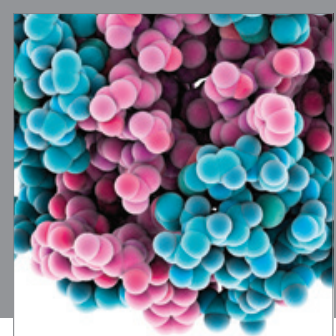

Journal of
Diabetes Research

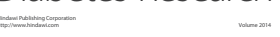

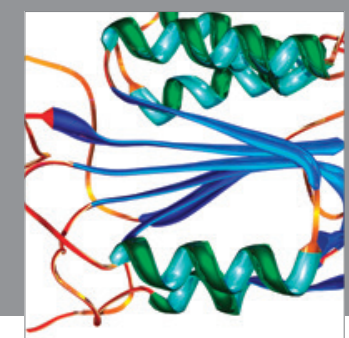

Disease Markers
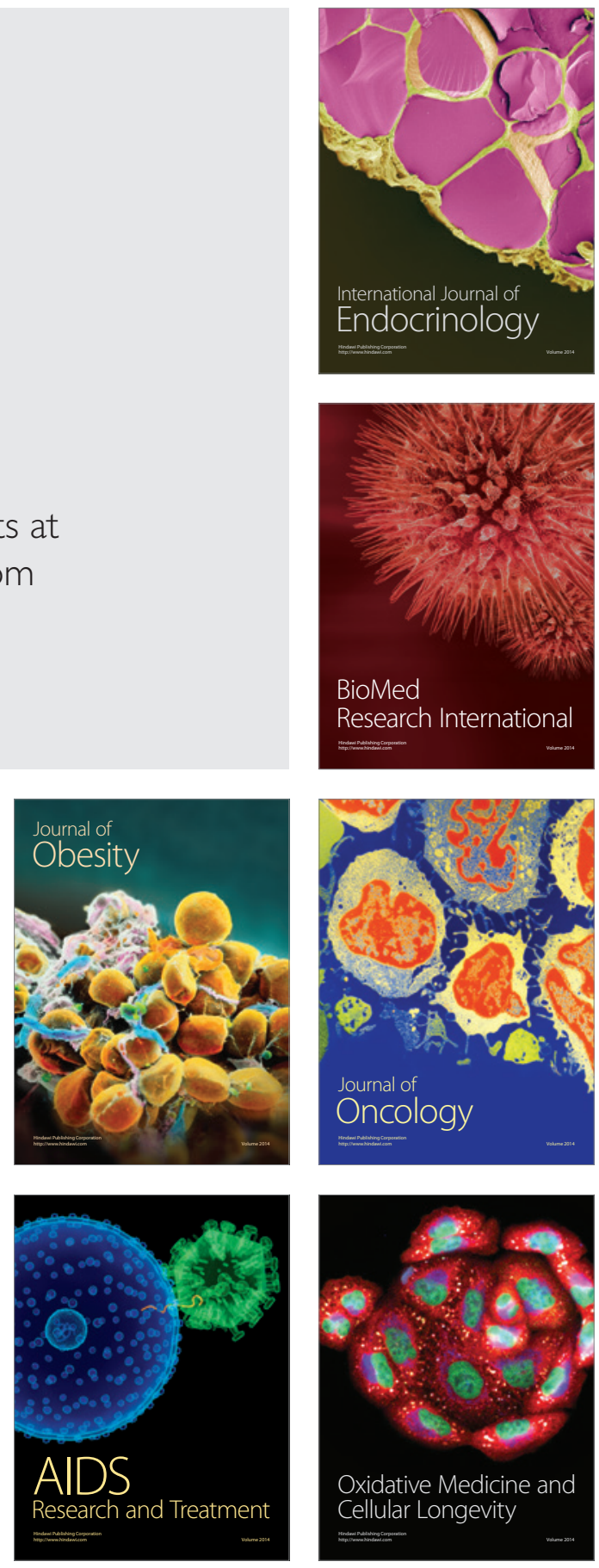